\title{
Immune Complexes Inhibit Antimicrobial Responses through Interleukin-10 Production \\ Effects in Severe Combined Immunodeficient Mice during Listeria Infection
}

Catherine S. Tripp, Karen P. Beckerman, and Emil R. Unanue

Department of Pathology, Washington University School of Medicine, St. Louis, Missouri 63110

\begin{abstract}
The presence of soluble antigen-antibody complexes renders mice highly susceptible to infection with the intracellular pathogen Listeria monocytogenes. In this report we show that this inhibition is manifest at the level of the innate immune response and is mediated by $\mathrm{IL-10}$. Like immunocompetent mice, mice with the severe combined immunodeficient mutation (SCID) injected with immune complexes died from a sublethal dose of $L$. monocytogenes. These mice were protected if pretreated with neutralizing antibodies to IL-10. In vitro, immune complexes stimulated IL-10 production by SCID splenocytes and splenic macrophages. Likewise, immune complexes inhibited TNF and IFN- $\gamma$ production by SCID splenocytes cultured with heat-killed- $L$. monocytogenes. This inhibition was reversed by neutralization of IL-10 but not IL-4 or TGF- $\beta$. Immune complexes and rIL10 inhibited cytokine production by SCID splenocytes if added before or simultaneously with heat-killed- $L$. monocytogenes. These data support a model in which immune complexes modulate host defense and the immune response by stimulating the production of $\mathrm{IL-10}$ from macrophages. $(J$. Clin. Invest. 1995. 95:1628-1634.) Key words: innate immunity $\bullet$ cytokines $\cdot$ macrophages $\cdot$ natural killer cell $\bullet$ microbial infection
\end{abstract}

\section{Introduction}

Antigen-antibody complexes interact with many cells of the immune system resulting in a wide variety of both positive and negative responses. The diversity of the cellular responses to immune complexes occurs through actions at several structurally distinct Fc receptors (reviewed in 1). Previously, our laboratory had shown a profound inhibitory effect of antigen-antibody complexes on the immune response to the intracellular pathogen Listeria monocytogenes. Formation of immune com-

Address correspondence to Emil R. Unanue, Department of Pathology, Washington University School of Medicine, $660 \mathrm{~S}$. Euclid Avenue, St. Louis, MO 63110. Phone: 314-362-7440; FAX: 314-362-4096. Catherine Tripp's present address is Department of Pediatrics, Washington University School of Medicine, $660 \mathrm{~S}$. Euclid Avenue, St. Louis, MO 63110. Karen Beckerman's present address is Department of Obstetrics, Gynecology and Reproductive Sciences, University of California, San Francisco, San Francisco General Hospital, San Francisco, CA 94110.

Received for publication 24 December 1993 and in revised form 21 November 1994.

J. Clin. Invest.

(C) The American Society for Clinical Investigation, Inc.

0021-9738/95/04/1628/07\$2.00

Volume 95, April 1995, 1628-1634 plexes to ovalbumin (OVA) ${ }^{1}$ in vivo concurrent with $L$. monocytogenes infection resulted in uncontrolled infection with high mortality (2). The immune complexes had to be present on the day before or on the day of infection to be inhibitory. Similarly, preformed immune complexes generated in vitro decreased the resistance to Listeria when injected into mice simultaneously with Listeria infection (3).

Decreased resistance to Listeria paralleled the inhibition of several parameters of immunologic function. Specifically, immune complexes inhibited macrophage class II MHC molecule expression induced by IFN- $\gamma$ in vivo (3) and in vitro (4, $5)$ and this correlated with a decrease in antigen presentation by these cells (5). Also, immune complexes inhibited the nonspecific tumoricidal response of macrophages $(5,6)$, as well as natural killer (NK) cell activity (7). Early research on the mechanism of immune complex inhibition determined that neither complement nor inhibitory arachidonate metabolites such as $\mathrm{PGE}_{2}$ and $\mathrm{PGI}_{2}$ were the mediators of the inhibition. However, the exact mechanism by which immune complexes increased the susceptibility to Listeria has remained undetermined.

Listeria infection in mice can be separated into two phases: an early $T$ cell-independent phase where IFN- $\gamma$ is rapidly produced by NK cells, and a later T cell-dependent phase involving both $\mathrm{CD}^{+}{ }^{+}$and $\mathrm{CD}^{+} \mathrm{T}$ cells (reviewed in 8, 9). The $\mathrm{T}$ cell-independent phase can best be studied in mice with the severe combined immunodeficiency (SCID) mutation. During Listeria infection in SCID mice, IFN- $\gamma$ production by NK cells is regulated by at least three macrophage derived cytokines (10-13). Both IL-12 and TNF- $\alpha$ are essential costimulators of IFN- $\gamma$ production $(10,13,14)$. In contrast, IL-10 inhibits NK cell production of IFN- $\gamma$ as well as macrophage production of TNF and IL-12 $(10,15)$. Likewise, IL-10 inhibits class II MHC molecule expression on human monocytes (16), IFN- $\gamma$ production by Th1 clones (17), and the production of many macrophage/monocyte cytokines (18). Thus, IL-10 is predominantly an inhibitor of many immune effector functions (reviewed in 19). In this report we use the model of Listeria infection in SCID mice to show that $\mathrm{IL}-10$ is induced by immune complexes and inhibits macrophage and NK cell cytokine productions resulting in decreased resistance to the infection.

\section{Methods}

Mice. CB17/ICR SCID (SCID) mice (20) were bred in specific pathogen-free conditions at Washington University School of Medicine, St. Louis, MO. Within each experiment mice were age $(8-12 \mathrm{wk})$ and sex matched.

1. Abbreviations used in this paper: hk-LM, heat-killed Listeria monocytogenes; NK, natural killer; OVA, ovalbumin; SCID, severe combined immunodeficient mutation. 
Monoclonal antibodies, cytokines, and reagents. The anti-IL-4 monoclonal antibody, 11B11 $(10 \mu \mathrm{g} / \mathrm{ml})$, anti-IL-10 monoclonal antibodies, 2A5 and SXC-1 (10-20 $\mu \mathrm{g} / \mathrm{ml})$, and anti TGF $\beta-1,2,3$ monoclonal antibody ( $10 \mu \mathrm{g} / \mathrm{ml}$; Genzyme Corp., Boston, MA) were described previously $(21,22)$. Mouse rIL-10 $(38,000 \mathrm{U} / \mathrm{ml})$ was obtained from PharMingen (San Diego, CA) and human rIL-2 $\left(2 \times 10^{5} \mathrm{U} / \mathrm{ml}\right.$ used at $200 \mathrm{U} / \mathrm{ml}$ ) was a gift from Hoffmann-La Roche (Nutley, NJ). The antibodies and mouse recombinant cytokines used for the IFN- $\gamma$ and TNF ELISAs, gifts from R. D. Schreiber (Washington University School of Medicine), were previously described $(23,24)$. The ELISA for IL-10 (22) was performed in two ways with similar results. Dynalon Products (Rochester, NY) or Nunc (Roskilde, Denmark) immuno 96well flat-bottomed plates were coated with anti IL-10 antibody, 2A5 (3-5 $\mu \mathrm{g} / \mathrm{ml}, 0.075 \mathrm{ml} /$ well) overnight at $4^{\circ} \mathrm{C}$ in $0.05 \mathrm{M}$ carbonate buffer, pH 9.6. Mouse rIL-10 (3-200 U/ml) or tissue culture supernatants to be tested were next allowed to bind overnight at $4^{\circ} \mathrm{C}$. The rIL10 was diluted into the same media as the tissue culture samples. Next, anti-IL-10 antibody, SXC-1 $(1 \mu \mathrm{g} / \mathrm{ml}, 0.1 \mathrm{ml} /$ well $)$ was allowed to bind at room temperature for $2 \mathrm{~h}$ followed by rabbit anti-mouse $\mathrm{Ig}, \mu$ chain specific conjugated to peroxidase (1:3,000 dilution, $0.1 \mathrm{ml} /$ well, USB Biologicals, Cleveland, $\mathrm{OH}$ ) also for $2 \mathrm{~h}$ at room temperature. The plates were developed with ABTS (Boehringer Mannheim GmbH, Mannheim, Germany) and $\mathrm{H}_{2} \mathrm{O}_{2}$, then read at OD 414. Alternatively, plates were coated with the $2 \mathrm{~A} 5$ monoclonal antibody and incubated with rIL-10 as described above. Next, biotinylated $2 \mathrm{~A} 5(0.1 \mathrm{ml} /$ well $)$ was allowed to bind at room temperature for $2 \mathrm{~h}$ followed by strepavidin-peroxidase conjugate $(1: 3,000,0.1 \mathrm{ml} /$ well; Zymed Laboratories, Inc., San Francisco, CA) for $2 \mathrm{~h}$ at room temperature. The plates were developed as described above. All of the steps of these ELISAs were performed in the same supplemented RPMI 1640 medium containing $10 \%$ FCS media used for tissue culture samples.

Immunizations. Preparation of anti-OVA serum was done as described previously (3). Briefly, OVA (Sigma Chemical Co., St. Louis, $\mathrm{MO}$ ) was dissolved in PBS, sterilized by filtration, and emulsified in a 1:1 mixture with complete Freund's adjuvant (Difco Laboratories Inc., Detroit, MI). BALB/c mice (Jackson Laboratories, Bar Harbor, ME) were then immunized with $100 \mu \mathrm{g}$ OVA $(200 \mu \mathrm{l})$ and secondary challenge was done with $50 \mu \mathrm{g}$ OVA in the same adjuvant $4 \mathrm{wk}$ later. Mice were serially bled every 2 wk until the titer of OVA-specific antiserum was $>1: 100,000$ by solid phase ELISA. At that time, the mice were exsanguinated and the anti-OVA serum was collected after centrifugation at $2,500 \mathrm{~g}$ for $10 \mathrm{~min}$. Pooled sera from several mice were incubated at $56^{\circ} \mathrm{C}$ for $1 \mathrm{~h}$, centrifuged at $50,000 \mathrm{~g}$ for $30 \mathrm{~min}$, sterilized by filtration $(0.22 \mu \mathrm{m})$, and stored at $-20^{\circ} \mathrm{C}$ until use. Normal mouse serum from unimmunized mice treated in the same fashion was used as a nonspecific antisera control ( 3 ). The IgG fraction of anti-OVA serum was purified using protein A-Sepharose column chromatography (Bio-Rad Laboratories, Hercules, CA).

Generation of immune complexes in vitro. Anti-OVA serum or normal mouse serum at a final concentration of 1:20 (5\%) diluted in pyrogen-free saline (in vivo) or in media (in vitro) was incubated with $0.5 \mathrm{mg}$ of OVA or BSA as described previously (3). Also, varying concentrations of the purified anti-OVA IgG fraction was incubated with varying concentrations of OVA in media. Immune complexes were allowed to form at room temperature for $4 \mathrm{~h}$. These immune complexes were injected intraperitoneally for the in vivo experiments $(0.5 \mathrm{ml} /$ mouse, corresponding to $0.025 \mathrm{ml}$ neat serum) or further diluted with media for the in vitro experiments to the concentrations shown in individual figures.

Infection. Live $L$ monocytogenes, stored in $20 \%$ glycerol/PBS at $-70^{\circ} \mathrm{C}$, were thawed once, diluted in pyrogen-free saline, and $3 \times 10^{3}$ bacteria were injected intraperitoneally $\left(\mathrm{LD}_{50}=1 \times 10^{4}\right)$. Survival was monitored with time after the initiation of infection while mice were housed in pathogen-free conditions. When preformed immune complexes and the monoclonal antibody, 2A5, were simultaneously injected, the order of injection was always $2 \mathrm{~A} 5(250 \mu \mathrm{g} / 0.5 \mathrm{ml}$ per pyrogen-free saline) intraperitoneally followed $1-2 \mathrm{~h}$ later by preformed immune complexes intraperitoneally followed $1-2 \mathrm{~h}$ later by Listeria $\left(3 \times 10^{3}\right.$ bacteria $/ 0.5 \mathrm{ml}$ saline $)$. Saline was injected into mice not receiving immune complexes or $2 \mathrm{~A} 5$.

Quantitation of infection and macrophage I-A expression. The number of $L$ monocytogenes per spleen were quantitated on day 3 of infection by homogenizing individual spleens in PBS containing $0.05 \%$ Triton X-100 and then plating serial dilutions onto brain-heart infusion agar (Difco Laboratories Inc.) (25). Bacterial colonies were quantitated after $24 \mathrm{~h}$ of growth at $37^{\circ} \mathrm{C}$. Peritoneal macrophages from the same animals were isolated by lavage with supplemented RPMI 1640 media containing 10\% FCS (Hyclone Laboratories, Logan, UT) as described previously (10). $L$. monocytogenes infection elicited $2-4 \times 10^{6}$ peritoneal exudate cells/mouse regardless of in vivo treatment. The peritoneal exudate macrophages (1-2 $\times 10^{5}$ cells) were allowed to adhere to glass coverslips for $4 \mathrm{~h}$ at $37^{\circ} \mathrm{C}$, at which time the nonadherent cells were removed by three washes with media. The adherent cells made entirely of macrophages were fixed with $1 \%$ paraformaldehyde in media for $10-15 \mathrm{~min}$ at $37^{\circ} \mathrm{C}$. Coverslips were stored at $4^{\circ} \mathrm{C}$ in PBS. I-A expression was quantitated by immunofluorescence as described (26) using MKD6 anti-I-A ${ }^{d}$ monoclonal antibody followed by fluoresceinconjugated $F\left(a^{\prime}\right)_{2}$ rabbit anti-mouse IgG. The percent of I-A ${ }^{d}$ positive macrophages in untreated SCID mice ranged from 4 to $20 \%(25,26)$. The data represent the mean $\pm \mathrm{SE}$ of values derived from individual mice and there were four mice per experimental group. This experiment was done once in SCID to verify the original observation made in immunocompetent mice (3).

Tissue culture. SCID splenocytes were cultured in supplemented RPMI 1640 containing 10\% FCS (Hyclone Laboratories) as previously described (10). All reagents were free of lipopolysaccharide as determined by the Limulus assay (Whittaker M. A. Bioproducts, Walkersville, MD). OVA was depleted of lipopolysaccharide by incubation with polymixin B-agarose gel (Boehringer Mannheim $\mathrm{GmbH}$ ). Briefly, single-cell suspensions from spleens of uninfected SCID mice were cultured at $2.5 \times 10^{6}$ cells $/ \mathrm{ml}$ in a total vol of $0.2 \mathrm{ml}$ in a 96-well flatbottom plate. All experiments had $200 \mathrm{U} / \mathrm{ml}$ of rIL-2 for maximal IFN$\gamma$ production (10). Reagents were added to the splenocyte cultures as described in each figure legend and the supernatants were harvested after $48 \mathrm{~h}$ of stimulation with heat-killed $L$. monocytogenes (hk-LM). IFN- $\gamma$ and TNF were measured in the tissue culture supernatants by ELISA. These supernatants were stable at $-40^{\circ} \mathrm{C}$ for weeks. Minimal or no TNF and IFN- $\gamma$ were produced from SCID splenocytes unless hk-LM was added (10). The data represent the mean \pm SE of 3 to 5 splenocyte cultures; each condition within an experiment was done in triplicate. The data are expressed as percent control because the IFN- $\gamma$ production in response to hk-LM varied from 500 to $3,000 \mathrm{U} / \mathrm{ml}$ in different splenocyte preparations.

Splenic macrophages were isolated by panning with anti-I- $\mathrm{A}^{\mathrm{d}}$ monoclonal antibody, MKD6, and macrophage-specific monoclonal antibody, F4/80 (27). $2 \times 10^{7}$ SCID splenocytes were incubated for $1.5 \mathrm{~h}$ at $37^{\circ} \mathrm{C}$ on antibody-coated $60-\mathrm{mm}$ tissue culture wells $(10 \mu \mathrm{g} / \mathrm{ml}$ of each antibody in $0.05 \mathrm{M}$ carbonate buffer, $\mathrm{pH} 9.6$, overnight, $4^{\circ} \mathrm{C}$ ). The nonadherent population was removed by washing with complete media. SCID splenocytes $\left(2 \times 10^{7}\right)$, panned splenic macrophages, or the nonadherent cells (from $2 \times 10^{7}$ splenocytes) were stimulated in $2 \mathrm{ml}$ media with hk-LM $\left(2 \times 10^{7}\right.$ bacteria/ml $)$ and/or preformed immune complexes at the concentration indicated in Table $\mathrm{I}$.

\section{Results}

The production of IFN- $\gamma$ is required for survival during infection with $L$. monocytogenes in immunocompetent and SCID mice $(25,28,29)$. Listeriosis in SCID mice results in chronic infection (25), since unlike immunocompetent mice, SCID mice lack specific $\mathrm{T}$ cell immunity. However, the early innate immune response involving the interaction between macrophages and NK cells resulting in IFN- $\gamma$ production is necessary to control the infection in both SCID (11) and immunocompetent mice (29). 
Table I. IL-10 Is Produced by SCID Splenocytes and Splenic Macrophages in Response to Preformed Immune Complexes and $h k-L M$

\begin{tabular}{lcc}
\hline & \multicolumn{2}{c}{$\mathrm{IL}-10(\mathrm{U} / \mathrm{ml})$} \\
\hline & $-h k-L M$ & $+h k-L M$ \\
(A) Splenocytes & & \\
$\quad$ None & $1 \pm 3$ & $5 \pm 5$ \\
$\quad$ Immune complexes & $14 \pm 9$ & $23 \pm 15$ \\
(B) Splenic macrophages & & \\
None & n.d. & $21 \pm 12$ \\
Immune complexes & n.d. & $45 \pm 3$ \\
& & \\
\hline
\end{tabular}

(A) SCID splenocytes were cultured and stimulated with preformed immune complexes (1\%) in the absence or presence of hk-LM for 48 h. IL-10 was measured in the supernatant by ELISA. The normal mouse serum or anti-OVA serum did not contain any measurable IL-10. Normal mouse serum (1\%) preincubated with OVA did not stimulate SCID splenocytes to produce any IL-10. The data represent the mean \pm SE of five separate spleen cell preparations. (B) An enriched population of SCID splenic macrophages were cultured and stimulated with preformed immune complexes ( $100 \mu \mathrm{g} / \mathrm{ml}$ anti-OVA IgG plus $15 \mu \mathrm{g} / \mathrm{ml}$ OVA) in the presence of hk-LM for $48 \mathrm{~h}$. The data represent the mean $\pm \mathrm{SE}$ of two separate cell preparations, each done in triplicate. Anti-OVA-IgG plus OVA alone contained no IL-10. n.d., not done. The same number of nonadherent cells stimulated with hk-LM in the absence and presence of immune complexes had no detectable IL-10.

In previous studies we showed that immunocompetent mice immunized with OVA were highly susceptible to infection if challenged with OVA at the same time as a sublethal infection with Listeria (2). This susceptibility was transferred by serum from the immune mice and not by $T$ cells. Indeed, transfer of serum containing anti-OVA antibodies together with OVA, so to form immune complexes, rendered the mice highly sensitive to the infection. The IgG fraction of serum and specifically the anti-OVA antibodies were entirely responsible for the effect $(2,3)$. Immune complexes decreased the resistance to Listeria infection only if present on the day before or on the day of infection, implying a mechanism involving the early innate immune response to Listeria. So, this effect of anti-OVA serum together with OVA, or preformed immune complexes, on the early phase of the immune response was now studied using Listeriosis in the SCID mice. When preformed immune complexes were administered simultaneously with a sublethal dose of Listeria there was an increased mortality from the infection (Fig. $1 A$ ), similar to immunocompetent mice treated in the same fashion shown previously $(2,3)$. Furthermore, this increased susceptibility to Listeria infection in the presence of immune complexes correlated with increased Listeria numbers in the spleen and decreased peritoneal macrophage class IIMHC molecule expression (Fig. $1 B$ ), also shown previously $(2,3)$. Controls indicated that the response was specific to the combined antigen-antibody complex. Thus, the decreased resistance to infection by immune complexes was independent of the presence of lymphocytes in the host.

The early macrophage-NK cell interaction resulting in IFN$\gamma$ production during Listeriosis is exquisitely regulated by the production of TNF- $\alpha$, IL-12, and IL-10 $(10,12,13)$. Specifically, IL-10 inhibits the productions of TNF, IL-12, and IFN- $\gamma$ by SCID splenocytes stimulated with hk-LM. SCID splenocyte
A

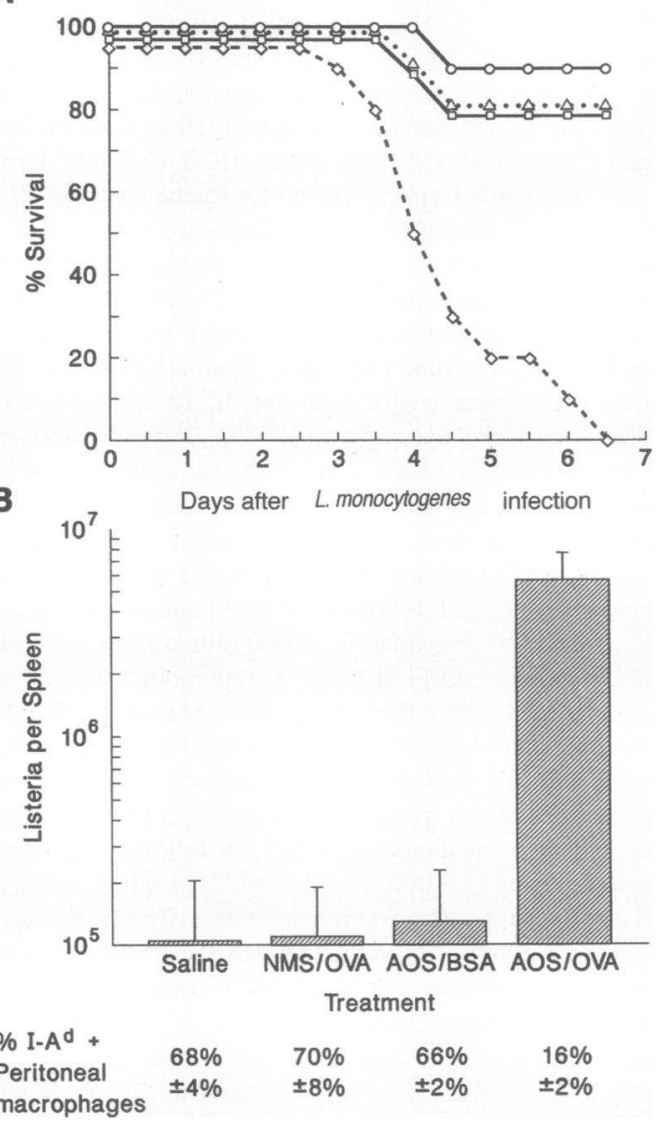

Figure 1. Preformed immune complexes decrease resistance to Listeria in SCID mice. Mixtures of normal mouse serum (NMS) or anti-OVAserum $(A O S)$ plus OVA or BSA were made in vitro as described in Methods. $0.5 \mathrm{ml}$ of anti-OVA-serum + OVA $(\diamond)$, normal mouse serum + OVA ( $\square$ ), anti-OVA-serum + BSA $(\Delta)$, or saline $(0)$ at a final concentration of $5 \%$ serum was injected intraperitoneally concomitantly with $3 \times 10^{3}$ live Listeria. $(A)$ Survival was monitored with time after the initiation of infection. The data represent two experiments containing five mice in each group per experiment. The data points are slightly displaced around each whole percentage for clarity. $(B)$ Quantitation of listerial burden in the spleen and I-A $\mathrm{A}^{\mathrm{d}}$ expression on peritoneal macrophages was done on day 3 of infection as described in Methods. The data represent the mean $\pm S E$ of four mice per group in one experiment.

cultures contain both macrophages and NK cells. To determine whether the inhibition by immune complexes could be due to IL-10 production, we first examined the effects of immune complexes on the production of IL-10 by SCID splenocytes and splenic macrophages (Table 1 ). IL-10 production by SCID splenocytes was stimulated by immune complexes in the absence and presence of hk-LM. Note, the amount of IL-10 production in response to immune complexes by splenic macrophages could account for that production seen by the unfractionated splenocyte cultures. The nonadherent cells which contained the NK cells did not produce $\mathrm{IL}-10$ in response to immune complexes.

Since immune complexes augmented $\mathrm{IL}-10$ production in response to hk-LM from SCID splenocytes, we evaluated their effects on IFN- $\gamma$ (Fig. $2 A$ ) and TNF (Fig. $2 B$ ) productions by these cultures. Immune complexes also inhibited hk-LMstimulated IFN- $\gamma$ and TNF production from SCID splenocytes. 


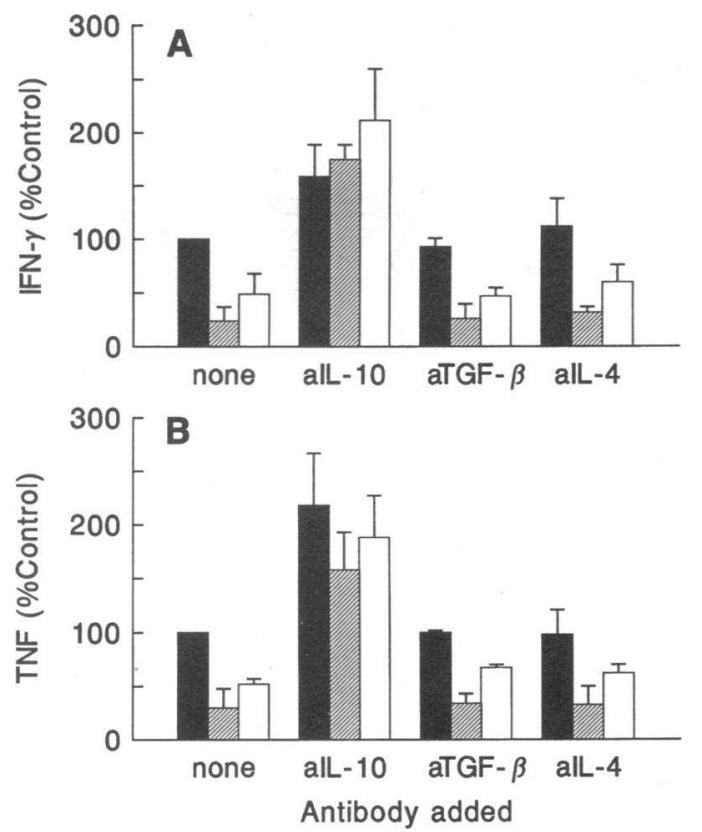

Figure 2. Preformed immune complexes inhibit hk-LM-induced IFN$\gamma$ and TNF production from SCID splenocytes, reversal by anti-IL-10 antibodies. SCID splenocytes were cultured as described in Methods and stimulated with $2.5 \times 10^{6} \mathrm{hk}-\mathrm{LM} / \mathrm{ml}$ in the absence $(\square)$ or presence of preformed immune complexes at $1(\boldsymbol{\nabla})$ and $0.1 \%$ (口). Monoclonal antibodies (10-20 $\mu \mathrm{g} / \mathrm{ml})$ to IL-10, TGF- $\beta$, or IL-4 were added simultaneously with the hk-LM and immune complexes, as indicated. Data are shown for anti-IL-10, 2A5, and similar results were obtained with SXC1. IFN- $\gamma(A)$ and TNF $(B)$ were measured by ELISA in the supernatants after $48 \mathrm{~h}$ of stimulation with hk-LM. The data represent the mean $\pm S E$ of three spleen cell preparations expressed as percent control of hk-LM stimulation alone.

Addition of neutralizing antibody to IL-10 augmented hk-LMinduced cytokine production, as shown previously (10), but also reversed the inhibition caused by immune complexes. Neutralization of two other inhibitory cytokines, TGF- $\beta$ or IL-4, caused no change in hk-LM-induced cytokine synthesis, and did not reverse immune complex suppression of IFN- $\gamma$ and TNF productions (Fig. 2). Thus, immune complex inhibition of hk-LM-induced cytokine production was reversed specifically by neutralization of IL-10.

The inhibition of SCID splenocyte IFN- $\gamma$ production by immune complexes was specific and dose dependent (Fig. 3 ). Normal mouse serum plus OVA did not cause significant inhibition except at very high concentrations as demonstrated in vitro previously (4). Neutralization of IL-10 resulted in augmented IFN- $\gamma$ production in the absence or presence of immune complexes or of normal mouse serum plus OVA at all concentrations. However, at high concentrations of immune complexes, neutralization of IL-10 did not always augment IFN- $\gamma$ production to control levels. For example, at $0.1,0.5$, and $1 \%$ concentrations of immune complexes in the presence of anti-IL-10 antibody, the production of IFN- $\gamma$ was still below that of normal mouse serum controls (Fig. $3 \mathrm{~B}$ ). The extent of augmentation by anti-IL-10 antibody, albeit always present, varied as can be seen by comparing Figs. 2, 3, and 5. Overall, these data suggest that immune complex-stimulated IL-10 production may not be the only mechanism for the inhibition of cytokine production
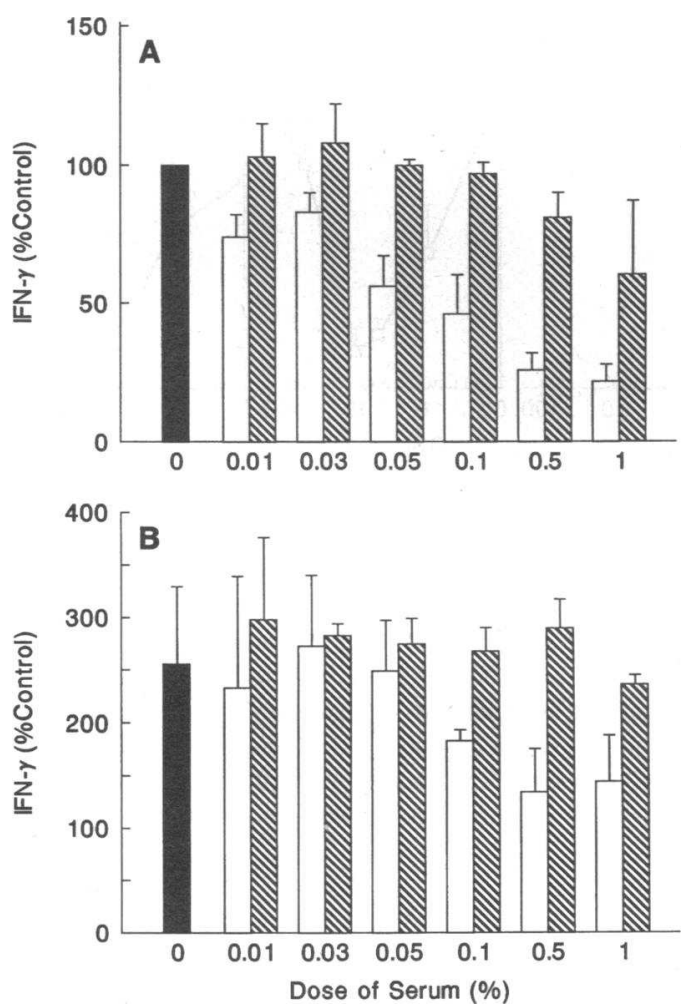

Figure 3. Preformed immune complexes inhibit hk-LM-induced SCID splenocyte IFN- $\gamma$ production specifically, in a dose-dependent fashion. Immune complexes were prepared as described in Methods and then diluted with complete media to the indicated concentrations. SCID splenocytes were cultured and stimulated with hk-LM simultaneously with preformed immune complexes $(\square)$ or normal mouse serum + OVA $(\square)$ in the absence $(A)$ or presence $(B)$ of anti-IL-10 antibody 2A5. IFN- $\gamma$ production was measured by ELISA in the supernatant after 48 $h$ of stimulation with hk-LM. The data represent the mean $\pm S E$ of three spleen cell preparations expressed as percentage of control of hk-LM stimulation alone.

from SCID splenocytes, particularly at the higher concentrations of immune complexes.

The IgG fraction of the anti-OVA serum, when incubated with the appropriate concentration of OVA as to form immune complexes, was entirely responsible for the inhibition of SCID splenocyte IFN- $\gamma$ production seen with unfractionated OVAimmune serum and OVA (Fig. 4). No inhibition was seen by IgG alone or in OVA excess, supporting the role for preformed immune complexes of a requisite size regulating this inhibition. Comparable reversal of this inhibition, as that seen in Fig. 3, could also be accomplished with purified anti-OVA IgG plus OVA immune complexes and anti-IL-10 antibodies. Again, the level of reversal was dependent on the concentration of immune complexes (data not shown). For example, at low doses of purified immune complexes (Fig. $4 A$ ), 229 $\pm 53 \%$ control IFN$\gamma$ production was observed in the presence of anti-IL-10 antibody, whereas at the higher doses of purified immune complexes (Fig. $4 C$ ) only $138 \pm 24 \%$ control IFN- $\gamma$ production was seen, similar to the findings with unfractionated anti-OVA serum plus OVA (Fig. $3 \mathrm{~B}$ ).

IL-10 inhibits a number of immunologic functions (19). To be inhibitory, IL-10 must be present before or simultaneously with the inducing stimulus. Likewise, immune complexes gen- 


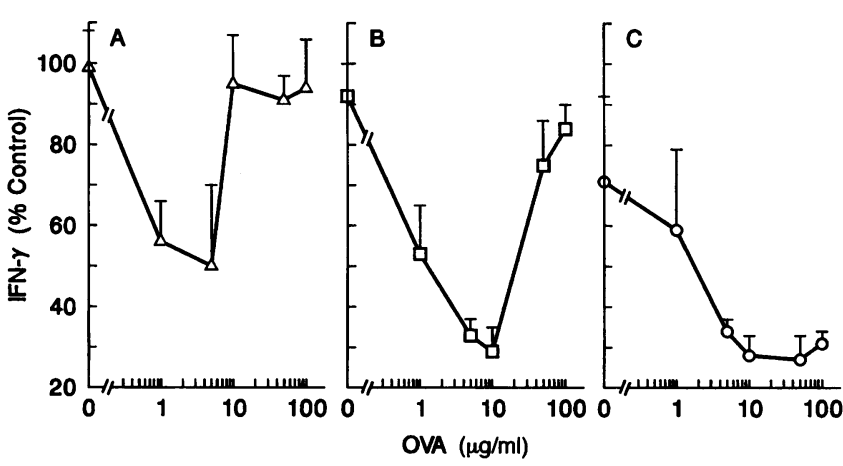

Figure 4. The purified anti-OVA IgG fraction plus OVA inhibits hkLM-induced SCID splenocyte IFN- $\gamma$ production and is dependent on the dose of anti-OVA IgG and OVA used. Immune complexes were allowed to form in vitro by incubating varying concentrations of purified anti-OVA IgG ([A] $50 \mu \mathrm{g} / \mathrm{ml},[B] 100 \mu \mathrm{g} / \mathrm{ml}$, and [C] $500 \mu \mathrm{g} / \mathrm{ml})$ and OVA together as described in Methods. SCID splenocytes were cultured and stimulated with hk-LM simultaneously with these preformed immune complexes. IFN- $\gamma$ production was measured by ELISA in the supernatant $48 \mathrm{~h}$ later. The data represent the mean $\pm S E$ of three spleen cell preparations expressed as percentage of control of hk-LM stimulation alone.

erated de novo in immunocompetent mice were required to be present on the same day or $1 \mathrm{~d}$ before infection to cause decreased resistance to Listeria (2). Thus, there is a specific window of time during which IL-10 or immune complexes can exert their inhibition. This narrow timing applied to immune complex inhibition of hk-LM-induced IFN- $\gamma$ production in vitro as well (Fig. 5). Immune complexes, like exogenous rIL10 , inhibited hk-LM-stimulated IFN- $\gamma$ production by SCID splenocytes only if added before or simultaneously with the hkLM (Fig. $5 \mathrm{~A}$ ). Addition of immune complexes or rIL-10 $6 \mathrm{~h}$ after hk-LM failed to inhibit IFN- $\gamma$ production. Again, the effects of both immune complexes and rIL-10 were reversed by the addition of neutralizing antibody to IL-10 (Fig. $5 \mathrm{~B}$ ).

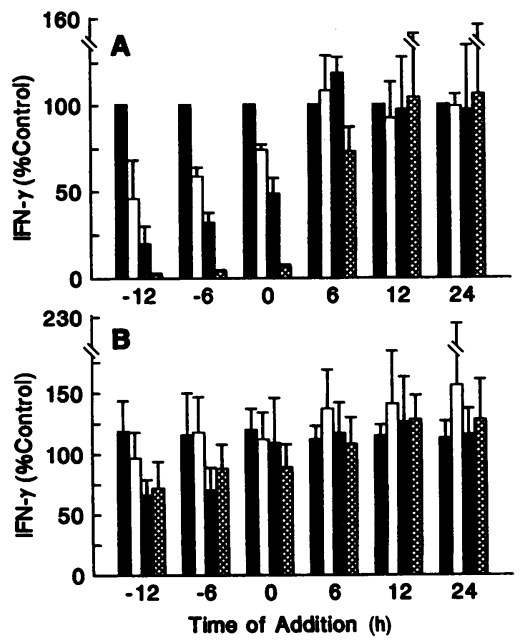

Figure 5. Inhibition of hk-LM-induced IFN- $\gamma$ production by SCID splenocytes by preformed immune complexes occurs with the same time course as mouse rIL-10. Preformed immune complexes at 0.1 ( $\square$ ) and $1 \%$ ( $\square$ ) final serum concentration or mouse rIL-10 (圈, $10 \mathrm{U} /$ $\mathrm{ml}$ ) were added to SCID splenocytes at the indicated times in the absence $(A)$ or presence $(B)$ of anti-IL-10 antibody, 2A5. The cultures were stimulated with

hk-LM at time 0 . Control without treatment with immune complexes or IL-10 is indicated for each time point ( $\bullet$ Culture supernatants were collected at $48 \mathrm{~h}$ after the addition of hk-LM and IFN- $\gamma$ production in the supernatants was measured by ELISA. The data represent the mean $\pm \mathrm{SE}$ from three separate spleen cell cultures and are expressed as the percent control of hk-LM stimulation alone at each time point.
A

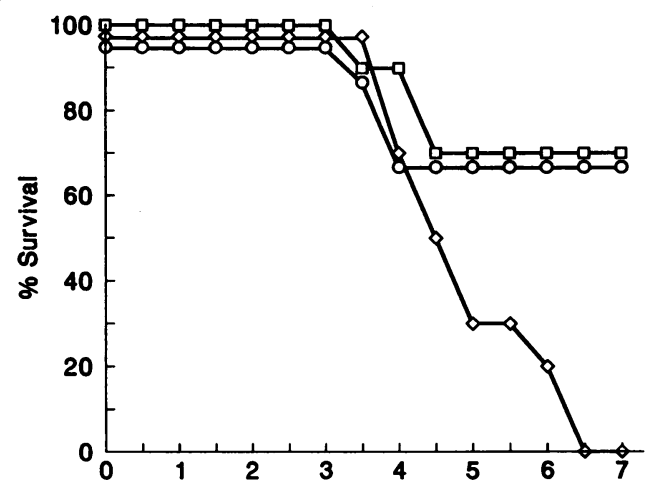

B

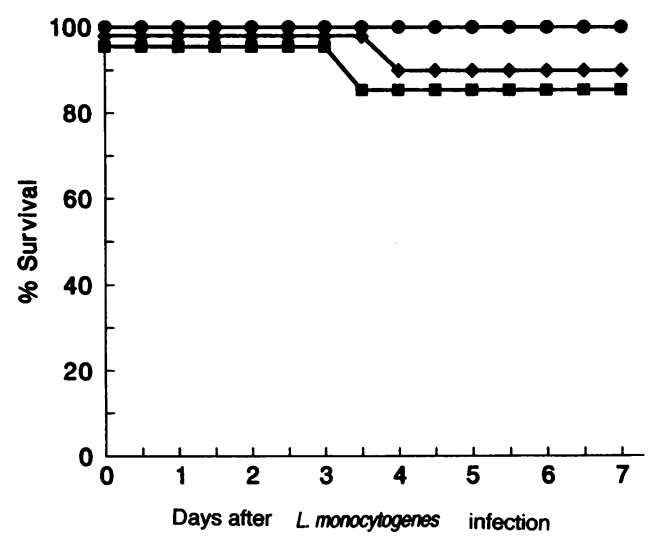

Figure 6. Neutralization of IL-10 in vivo protects mice from the decreased resistance to Listeria caused by preformed immune complexes. Mixtures of anti-OVA serum + OVA $(\diamond, \diamond)$, anti-OVA serum + BSA $(\square, \square)$, or saline $(O, \bullet)$ were made in vitro as described in Methods and injected in the absence $(A)$ or presence $(B)$ of neutralizing antibody to IL-10, 2A5. Mice were concurrently infected with $3 \times 10^{3}$ live Listeria and survival was monitored after the initiation of infection. The data represent two experiments containing five mice in each group per experiment. The data points are slightly below or slightly above each whole percentage for clarity.

Since IFN- $\gamma$ production is necessary for the survival of Listeriosis for both SCID and immunocompetent mice, and since immune complexes inhibited hk-LM-induced IFN- $\gamma$ production via IL-10 production in vitro, we next evaluated the role of IL-10 on immune complex inhibition in vivo. SCID mice were treated with preformed immune complexes during Listeria infection in the absence and presence of neutralizing antibody to IL-10 (Fig. 6). As shown in Fig. 1, immune complexes decreased the survival to Listeria infection compared with saline or normal mouse serum plus OVA treated mice (Fig. $6 \mathrm{~A}$ ). Neutralization of IL-10 in vivo protected these mice from the inhibitory effects of immune complexes (Fig. $6 \mathrm{~B}$ ). Thus, these data strongly argue that immune complexes inhibit the innate immune response through stimulation or production of the inhibitory cytokine, IL-10.

\section{Discussion}

The present results confirm the original studies of Virgin et al. that showed antigen-antibody complexes profoundly inhibited resistance to Listeria infection $(2,3)$. We now showed that 
the inhibition took place during the $\mathrm{T}$ cell-independent, innate immune response to Listeria and was reversed by administering neutralizing monoclonal antibodies to IL-10. We did not directly examine IL-10 production in vivo, although the in vitro studies presented here indicated that IL-10 was produced when SCID splenic macrophages were stimulated with immune complexes, and that immune complexes and mouse rIL-10 inhibited hk$\mathrm{LM}$-induced IFN- $\gamma$ production by SCID splenocytes. The latter process was reversed by addition of anti-IL-10 antibodies, as was the decreased resistance to Listeria in vivo. Thus, we concluded that the increased susceptibility to Listeria infection by immune complexes was primarily mediated by IL-10.

These studies underscore the delicate balance between stimulatory and inhibitory cytokines produced during an infectious process. This balance may be altered by a number of factors and circulating antigen-antibody seems to be one of them. Previously we showed that macrophages stimulated by hk-LM produced IL-10, along with IL-12, and TNF $(10,12,13)$. These stimulatory and inhibitory cytokines were also induced from peritoneal macrophages, and this conditioned media from these cells resulted in the production of IFN- $\gamma$ by NK cells in SCID splenocyte cultures (10). IFN- $\gamma$ production was augmented by neutralizing the IL-10, an observation confirmed in the results presented here. Exogenous IL-10 also directly inhibited macrophage production of TNF and presumably IL-12 as well as NK cell IFN- $\gamma$ production from these spleen cell cultures (10). Here we show that immune complexes, with or without hk-LM, stimulated more IL-10 production from SCID splenic macrophages. Although IL-12 production was not measured directly in response to immune complexes, the fact that immune complex inhibition is mediated by $\mathrm{IL}-10$ indicates that $\mathrm{IL}-12$ and TNF- $\alpha$. must be inhibited by the same mechanism shown previously.

Immune complexes are formed during the chronic stages of other infectious diseases. For example, circulating antigenemia and immune complexes are found in schistosomiasis $(30,31)$, malaria (32), and leprosy $(33,34)$. These immune complexes participate in the well-known inflammation and pathologies associated with these infections, particularly in the skin and kidney (35-37). As shown herein, immune complexes could also regulate the immune response by production of $\mathrm{IL}-10$. The production of IL-10 will inhibit two key interrelated responses: (a) the macrophage and NK cell interaction necessary to activate macrophages and develop protective innate immunity, and $(b)$ the generation of Th1 cells that produce IFN- $\gamma$ and IL-2 generating antigen-specific cellular immunity $(38-40)$. The productions of IL-10 and IL-12 determine either the inhibition or stimulation, respectively, of both of these interrelated responses ( 10 , 41,42 ) during Listeria infection. In toto the formation of $\mathrm{IL}$ 10 by immune complexes may decrease those protective mechanisms essential for many specific and nonspecific microbicidal functions.

One particularly pointed example is murine schistosomiasis where there is a downregulation of the Th1 response during chronic infection $(43,44)$. This inhibition can be mediated by the production of $\mathrm{IL}-10$ from CD4 ${ }^{+} \mathrm{T}$ cells $(43,45,46)$. However, perhaps Th1 downregulation may also be mediated by increased IL-10 production from macrophages stimulated with immune complexes. It is noteworthy in the context of our results that immune complexes are found in chronic schistosomiasis $(30,31)$. Indeed, adoptive transfer of serum or an $\mathrm{IgG}_{1}$ fraction, but not of lymphocytes from chronically infected mice, resulted in a reduction in the size of granulomas in acutely infected recipient mice $(47,48)$.

Finally, it is interesting to speculate that immune complexes may modulate autoimmune disease exacerbation via the production of IL-10. Concentrations of autoantibodies can become quite high during flares in these diseases (reviewed in 49). Autoantibody-antigen complexes may stimulate macrophage IL-10 production. In turn, IL-10 could then stimulate increased or prolonged expression $\mathrm{Fc} \gamma \mathrm{R}$, the receptor for $\mathrm{IgG}$, on the monocyte surface (50). Thus, a positive feedback loop is conceivable, involving increasing amounts of autoantibody-antigen complexes, stimulated $I L-10$, and sustained $F c \gamma R$ receptor expression; all may result in sustained inflammation and increased susceptibility to infections requiring a cellular immune response. The regulation of $\mathrm{IL}-10$ by immune complexes during both infection and autoimmunity adds yet another intriguing cytokine regulatory mechanism during the immune response.

\section{Acknowledgments}

We wish to thank Robert D. Schreiber, Kenneth M. Murphy, and John H. Russell for their advice.

This study was supported by grants from the National Institutes of Health (NIH). Catherine Tripp was supported by a training grant from the NIH and, in part, by the Department of Pediatrics at Washington University School of Medicine.

\section{References}

1. Ravetch, J. V., and J.-P. Kinet. 1991. Fc receptors. Annu. Rev. Immunol. 9:457-492.

2. Virgin, H. W., IV, and E. R. Unanue. 1984. Suppression of the immune response to Listeria monocytogenes. 1 . Immune complexes inhibit resistance. $J$. Immunol. 133:104-109.

3. Virgin, H. W., IV, G. F. Wittenberg, G. J. Bancroft, and E. R. Unanue. 1985. Suppression of immune response to Listeria monocytogenes: mechanism(s) of immune complex suppression. Infect. Immun. 50:343-353.

4. Virgin, H. W., IV, G. F. Wittenberg, and E. R. Unanue. 1985. Immune complex effects on murine macrophages. 1. Immune complexes suppress interferon- $\gamma$ induction of Ia expression. J. Immunol. 135:3735-3743.

5. Virgin, H. W., IV, E. A. Kurt-Jones, G. F. Wittenberg, and E. R. Unanue. 1985. Immune complex effects on murine macrophages. II. Immune complex effects on activated macrophages cytotoxicity, membrane Il-1 and antigen presentation. J. Immunol. 135:3744-3749.

6. Esparza, I., R. Green, and R. D. Schreiber. 1983. Inhibition of macrophage tumoricidal activity by immune complexes and altered erythrocytes. J. Immunol. 131:2117-2121.

7. Pedersen, B. K., B. S. Thomsen, and H. Nielsen. 1986. Inhibition of natural killer cell activity by antigen-antibody complexes. Allergy. 41:568-574.

8. Bancroft, G. J., R. D. Schreiber, and E. R. Unanue. 1991. Natural immunity: a $T$ cell independent pathway of macrophage activation, defined in the SCID mouse. Immunol. Rev. 124:5-24.

9. Kaufmann, S. H. E. 1993. Immunity to intracellular bacteria. Annu. Rev. Immunol. 11:129-163.

10. Tripp, C. S., S. F. Wolf, and E. R. Unanue. 1993. Interleukin-12 and tumor necrosis factor $\alpha$ are costimulators of interferon- $\gamma$ production by natural killer cells in severe combined immunodeficiency mice with listeriosis, and interleukin 10 is a physiologic antagonist. Proc. Natl. Acad. Sci. USA. 90:37253729.

11. Bancroft, G. J., R. D. Schreiber, G. C. Bosma, M. J. Bosma, and E. R. Unanue. 1987. A T cell-independent mechanism of macrophage activation by interferon- $\gamma$. J. Immunol. 139:1104-1107.

12. Bancroft, G. J., K. C. F. Sheehan, R. D. Schreiber, and E. R. Unanue 1989. Tumor necrosis factor is involved in the $\mathrm{T}$ cell-independent pathway of macrophage activation in SCID mice. J. Immunol. 143:127-130.

13. Wherry, J. C., R. D. Schreiber, and E. R. Unanue. 1991. Regulation of gamma interferon production by natural killer cells in SCID mice: roles of tumor necrosis factor and bacterial stimuli. Infect. Immun. 59:1709-1715.

14. Tripp, C. S., M. K. Gately, J. Hakimi, P. Ling, and E. R. Unanue. 1994 Neutralization of IL-12 decreases resistance to Listeria in SCID and C.B-17 mice; reversal by IFN- $\gamma$. J. Immunol. 152:1883-1887.

15. D'Andrea, A., M. Aste-Amezaga, N. M. Valiante, X. Ma, M. Kubin, and 
G. Trinchieri. 1993. Interleukin-10 (IL-10) inhibits human lymphocyte interferon $\gamma$-production by suppressing natural killer cell stimulatory factor/IL-12 synthesis in accessory cells. J. Exp. Med. 178:1041-1048.

16. de Waal Malefyt, R., J. Haanen, H. Spits, M. -G. Roncarolo, A. teVelde, C. Figdor, K. Johnson, R. Kastelein, H. Yssel, and J. E. de Vries. 1991. Interleukin10 (IL-10) and viral IL-10 strongly reduced antigen-specific human T cell proliferates by diminishing the antigen-presenting capacity of monocytes via downregulation of class II major histocompatibility complex expression. J. Exp. Med. 174:915-924.

17. Fiorentino, D. F., A. Zlotnik, P. Vieira, T. R. Mosmann, M. Howard, K. W. Moore, and A. O'Garra. 1991. IL-10 acts on the antigen-presenting cell to inhibit cytokine production by Th1 cells. J. Immunol. 146:3444-3451.

18. deWaal Malefyt, R., J. Abrams, B. Bennett, C. Figdor, and J. E. de Vries. 1991. Interleukin 10 (IL-10) inhibits cytokine synthesis by human monocytes: an autoregulatory role of IL-10 produced by monocytes. J. Exp. Med. 174:12091220.

19. Moore, K. W., A. O'Garra, R. de Waal Malefyt, P. Vieira, and T. R. Mosmann. 1993. Interleukin-10. Annu. Rev. Immunol. 11:165-190.

20. Bosma, G. C., R. P. Custer, and M. J. Bosma. 1983. A severe combined immunodeficiency mutation in the mouse. Nature (Lond.). 301:527-531.

21. O'Hara, J., and W. E. Paul. 1985. Production of a monoclonal antibody to and molecular characterization of B-cell stimulatory factor-1. Nature (Lond.). 315:333-336.

22. Mosmann, T. R., J. H. Schumacher, D. F. Fiorentino, J. Leverah, K. W. Moore, and M. W. Bond. 1990. Isolation of monoclonal antibodies specific for IL-4, IL-5, IL-6 and a new Th2-specific cytokine (IL-10), cytokine synthesis inhibitory factor by using a solid phase radioimmunoadsorbent assay. J. Immunol. 145:2938-2945.

23. Sheehan, K. C. F., N. Ruddle, and R. D. Schreiber. 1989. Generation and characterization of hamster monoclonal antibodies that neutralize murine tumor necrosis factors. J. Immunol. 142:3884-3893.

24. Schreiber, R. D., L. J. Hicks, A. Celada, N. A. Buchmeier, and P. W. Gray. 1985. Monoclonal antibodies to murine $\gamma$-interferon which differentially modulate macrophage activation and antiviral activity. J. Immunol. 134:16091618 .

25. Bancroft, G. J., M. J. Bosma, G. C. Bosma, and E. R. Unanue. 1986 Regulation of macrophage Ia expression in mice with severe combined immunodeficiency: induction of Ia expression by a T cell-independent mechanism. J. Immunol. 137:4-9.

26. Rogers, H. W., K. C. F. Sheehan, L. M. Brunt, S. K. Dower, E. R. Unanue, and R. D. Schreiber. 1992. Interleukin-1 participates in the development of antiListeria responses in normal and SCID mice. Proc. Natl. Acad. Sci. USA 89:1011-1015.

27. Ezekowitz, R. A., P. D. Stahl, J. M. Austyn, and S. Gordon. 1981. Surface properties of bacillus Calmette-Guerin-activated mouse macrophages. Reduced expression of mannose specific endocytosis, Fc receptors and antigen F4/80 accompanies induction of Ia. J. Exp. Med. 154:60-65.

28. Buchmeier, N. A., and R. D. Schreiber. 1985. Requirement of endogenous interferon-gamma production for resolution of Listeria monocytogenes infection Proc. Natl. Acad. Sci. USA. 82:7404-7408.

29. Dunn, P. L., and R. J. North. 1991. Early gamma interferon production by natural killer cells in important in defense against murine Listeriosis. Infect. Immun. 59:2892-2900.

30. Santoro, F., M. Capron, M. Joseph, R. Rousseaux-Prevost, and A. Capron. 1978. Circulating antigens and immune complexes in Schistosoma mansoniinfected rats. Characterization by radioimmunoprecipitation-PEG assay (RIPEGA). Clin. Exp. Immunol. 32:435-442.

31. Stevens, W. J., H. Fedmeir, C. H. Bridts, and A. A. Daffalla. 1983. IgC and IgE circulating immune complexes, total serum IgE and parasite related IgE in patients with mono- or mixed infection with Schistosoma mansoni and/or $S$. haematobium. Influence of therapy. Clin. Exp. Immunol. 52:142-152.
32. June, C. H., C. E. Cautreras, L. H. Perrin, P. H. Lambert, and P. A. Miescher. 1979. Circulating and tissue-bound immune complex formation in murine malaria. J. Immunol. 122:2154-2161.

33. Rojas-Espinosa, O., I. Mendez-Navarrete, and S. Estrada-Parra. 1972. Presence of Clq-reactive immune complexes in patients with leprosy. Clin. Exp. Immunol. 12:215-223.

34. Moran, C. J., J. L. Turk, G. Ryder, and M. F. R. Waters. 1972. Evidence for circulating immune complexes in Lepromatous leprosy. Lancet. ii 2:572-573.

35. Boonpucknavig, S., S. Wongsawang, V. Boonpucknavig, and N. Bhamarapravati. 1976. Serum-soluble malarial antigens and immune complex nephritis in plasmodium berghei berghei-infected mice. J. Trop. Med. Hyg. 79:116-119.

36. Drutz, D. J., and R. A. Gutman. 1973. Renal manifestations of leprosy: glomerulonephritis, a complication of erythema nodosum leprosum. Am. J. Trop. Med. Hyg. 22:496-502.

37. Ridley, M. J., and D. S. Ridley. 1983. The immunopathology of erythema nodosum leprosum: the role of extravascular complexes. Lep. Rev. 54:95-107.

38. Mosmann, T. R., H. Cherwinski, M. W. Bond, M. A. Giedlin, and R. L. Coffman. 1986. Two types of murine helper $T$ cell clones. 1. Definition according to profiles of lymphokine activities and secreted proteins. J. Immunol. 136:23482357.

39. Fiorentino, D. F., M. W. Bond, and T. R. Mosmann. 1989. Two types of mouse T helper cell. IV. Th2 clones secrete a factor that inhibits cytokine production by Th1 clones. J. Exp. Med. 170:2081-2095.

40. Mosmann, T. R., J. H. Schumacher, N. F. Street, R. Budd, A. O'Garra, T. A. T. Fong, M. W. Bond, K. W. M. Moore, A. Sher, and D. F. Fiorentino. 1991. Diversity of cytokine synthesis and function of mouse $\mathrm{CD} 4{ }^{+} \mathrm{T}$ cells. Immunol. Rev. 123:209-229.

41. Hsieh, C. -S., S. E. Macatonia, A. O'Garra, and K. M. Murphy. 1993. Pathogen-induced Thl phenotype development in CD4 $\alpha \beta$-TCR transgenic $\mathrm{T}$ cells is macrophage dependent. Int. Immunol. 5:371-382.

42. Hsieh, C. -S., S. E. Macatonia, C. S. Tripp, S. F. Wolf, A. O'Garra, and K. M. Murphy. 1993. Development of Th1 CD4+ T cells through IL-12 produced by Listeria-induced macrophages. Science (Wash, DC). 260:547-549.

43. Sher, A., R. T. Gazzinelli, I. P. Oswald, M. Clerici, M. Kullberg, E. J. Pearce, J. A. Berzofsky, T. R. Mosmann, S. L. James, H. C. Morse III, and G. M. Shearer. 1992. Role of T-cell derived cytokines on the down-regulation of immune responses in parasitic and retroviral infection. Immunol. Rev. 127:183-204.

44. Kullberg, M. C., E. J. Pearce, S. E. Hieny, A. Sher, and J. A. Berzofsky. 1992. Infection with Schistosoma mansoni alters Th1/Th2 cytokine responses to a non-parasite antigen. J. Immunol. 148:3264-3270.

45. Sher, A., D. Fiorentino, P. Caspar, E. Pearce, and T. Mosmann. 1991. Production of IL- 10 by CD4+ T lymphocytes correlates with down-regulation of Th1 cytokine synthesis in helminth infection. J. Immunol. 147:2713-2716.

46. Flores Villanueva, P. O., S. M. Chikunguwo, T. S. Harris, and M. J. Stadecker. 1993. Role of IL-10 on antigen-presenting cell function for Schistosomal egg-specific monoclonal $\mathrm{T}$ helper cell responses in vitro and in vivo. $J$. Immunol. 151:3192-3198.

47. Olds, G. R., R. Olveda, J. W. Tracy, and A. A. F. Mahmoud. 1982. Adoptive transfer of modulation of granuloma formation and hepatosplenic disease in murine Schistosomiasis japonica by serum from chronically infected animals. J. Immunol. 128:1391-1393.

48. Garb, K. S., A. B. Stavitsky, G. R. Olds, J. W. Tracy, and A. A. F. Mahmoud. 1982. Immune regulation in murine Schistosomiasis japonica: inhibition of in vitro antigen- and mitogen-induced cellular responses by splenocyte culture supernatants and by purified fractions from serum of chronically infected mice. J. Immunol. 129:2752-2758.

49. Naparstek, Y., and P. H. Plotz. 1993. The role of autoantibodies in autoimmune disease. Annu. Rev. Immunol. 11:79-104.

50. Te Velde, A. A., R. de Waal Malefijt, R. J. F. Huijbens, J. E. de Vries, and C. G. Figdor. 1992. IL-10 stimulates monocyte Fc $\gamma$ R surface expression and cytotoxic activity. Distinct regulation of antibody-dependent cellular cytotoxicity by IFN- $\gamma$, IL-4 and IL-10. J. Immunol. 149:4048-4052. 